\title{
Preface
}

\section{Evaluating online health information sources using a mixed methods approach: Part 2}

\author{
Vera Granikover, and Pierre Pluye ${ }^{\mathrm{b}}$

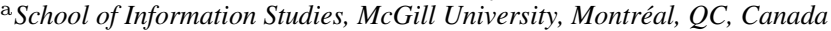 \\ ${ }^{\mathrm{b}}$ Department of Family Medicine, McGill University, Montréal, QC, Canada
}

Part one of the special issue on "Evaluating online health information sources using a mixed methods approach" (Granikov \& Pluye 2018, volume 34(4) of the journal), focused on literature reviews, their history, specific methods and tools, as well as what happens when research evidence becomes contradicted by new stronger evidence. In the second part of this series on evaluating online health information sources, we focus on innovative tools and health information literacy interventions and bring to our readers the results of research by members of the Information Technology Primary Care Research Group (ITPCRG) from the Department of Family Medicine at McGill University in Montréal, Canada (www.mcgill.ca/familymed/research/projects/itpcrg).

The quality and rigour of research methods are fundamental. Thus, the ongoing discussion and development of research methods used in Library and Information Science (LIS) is important for practitioners, researchers, educators, and students (Chu \& Ke, 2017; Julien et al., 2011). The first article by Hamzeh et al. is situated in this discussion. It addresses the quality of data collection instruments and presents the work on the Questionnaire Origin and Development Appraisal (QODA) tool. The QODA tool is intended to ensure the quality of origin and development of questionnaire dimensions and items. Given the continued relevance and popularity of questionnaire surveys in LIS research (Chu, 2015; Turcios et al., 2014), we envisage that this paper will inform all those who wish to design questionnaires not only in LIS but also in the social sciences and the humanities.

Just like the validity of research depends on the use of valid tools and rigorous methods, informed decision-making depends on having high-quality information. This brings us to the topic of information literacy, and specifically, health information literacy. At its core, information literacy can be defined as "the ability to think critically and make balanced judgements about any information we find and use" and "it empowers us as citizens to reach and express informed views and to engage fully with society" (Information Literacy Group, 2018, p. 3). Therefore, health information literacy "helps make informed choices relating to the health and wellbeing of individuals and their families" (Information Literacy Group, 2018, p. 5). 
Research evidence continues to demonstrate that lower health literacy is associated with poorer health outcomes and use of health services, for example, more hospitalizations and visits to the emergency, lower ability to understand labels and health instructions (Berkman et al., 2011). There is an argument that to improve health literacy, we need to reconsider the content and methods used to communicate health information, focussing on "more personal forms of communication and communitybased educational outreach" (Nutbeam, 2000, p. 267).

The article by Kaur proposes an interesting method to communicate health information, the photonovel. The findings of her literature review support the potential effectiveness of photonovels to communicate health information especially to those with lower literacy levels. This work is important given that $99 \%$ of the Canadian population aged between 18 and 29 use online consumer health information, more than $66 \%$ have a low level of health literacy (Centre francophone d'informatisation des organisations - CEFRIO, 2011; Hersberger, 2003; Ronson McNichol \& Rootman, 2016).

Situated in the discussion of the digital divide, El Sherif et al. share surprising findings on benefits related to the use of online consumer health information. Their research suggests that when using tailored high quality information (including audio/visual aids), consumers with lower levels of income and education report as many benefits as those with higher levels. This article is based on a study linking the Information Assessment Method questionnaire (www.mcgill.ca/iam) to an online information resource that provides free and reliable information on child development, education, well-being and health (https://naitreetgrandir.com).

The article by Dai et al. concludes Part 2 of this series by introducing an educational online program called Patient Information Aid. Two critical factors define this website, currently under development, from other health information literacy initiatives. First, its content and organization are based on research evidence from a participatory systematic mixed studies literature review and a qualitative study on outcomes of online consumer health information use (El Sherif et al., 2018; Pluye et al., 2019). Second, its design is guided by the principles of user-centred participatory design. Overall, the above-described articles aim to better understand and improve information practices, consumers' information literacy, ultimately contributing to better health.

In conclusion, there is much to gain from the collaboration between researchers in health and information disciplines. Such collaboration is vital to new discoveries and practice improvements. The articles in this issue focus on innovative methods and tools used in health research, which are transferable and potentially valuable to information professionals, students, educators, and researchers.

\section{References}

Berkman, N., Sheridan, S., Donahue, K., Halpern, D., \& Crotty, K. (2011). Low health literacy and health outcomes: An updated systematic review. Annals of Internal Medicine, 155(2), 97-107. doi: 10.7326/0003-4819-155-2-201107190-00005. 
Centre francophone d'informatisation des organisations - CEFRIO. (2011). Génération @ : Portrait de l'utilisation d'internet et de l'ordinateur par les aînés internautes du Québec. Retrieved from http:// www.cefrio.qc.ca/fileadmin/documents/Rapports/Rapport_synth\%C3\%A8se_version_finale.pdf.

Chu, H. (2015). Research methods in library and information science: A content analysis. Library \& Information Science Research, 37(1), 36-41.

Chu, H., \& Ke, Q. (2017). Research methods: What's in the name? Library and Information Science Research, 39(4), 284-294.

El Sherif, R., Pluye, P., Thoër, C., \& Rodriguez, C. (2018). Reducing negative outcomes of online consumer health information: A qualitative interpretive study with clinicians, librarians, and consumers. Journal of Medical Internet Research, 20(5). doi: doi:10.2196/jmir.9326.

Hersberger, J. (2003). Are the economically poor information poor? Does the digital divide affect the homeless and access to information? Canadian Journal of Library and Information Sciences, 27(3), 45-63.

Information Literacy Group. (2018). CILIP Definition of Information Literacy 2018. Retrieved from https://infolit.org.uk/ILdefinitionCILIP2018.pdf.

Julien, H., Pecoskie, J., \& Reed, K. (2011). Trends in information behavior research, 1999-2008: A content analysis. Library \& Information Science Research, 33(1), 19-24.

Nutbeam, D. (2000). Health literacy as a public health goal: A challenge for contemporary health education and communication strategies into the 21 st century. Health Promotion International, 15(3), 259-267. doi: 10.1093/heapro/15.3.259.

Pluye, P., El Sherif, R., Granikov, V., Hong, Q. N., Vedel, I., Galvao, M. C., Frati, F. E., Desroches, S., Repchinsky, C., Rihoux, B., Légaré, F., Burnand, B., Bujold, M. \& Grad, R. (2019). Health outcomes of online consumer health information: A systematic mixed studies review with framework synthesis. Journal of the Association for Information Science and Technology. doi: 10.1002/asi.24178.

Ronson McNichol, B., \& Rootman, I. (2016). Literacy and health literacy: New understandings about their impact on health. In D. Raphael (Ed.), Social determinants of health: Canadian perspectives (3rd ed., pp. 261-290). Toronto, Canada: Canadian Scholars' Press.

Turcios, M. E., Agarwal, N. K., \& Watkins, L. (2014). How much of library and information science literature qualifies as research? Journal of Academic Librarianship, 40(5), 473-479. 